\title{
Inventory Survey of the 2003 Zemmouri (Algeria) Earthquake: Case Study of Dergana City
}

\author{
Hassane Ousalem ${ }^{1}$ and Hakim Bechtoula ${ }^{2}$
}

Received 12 February 2004, accepted 29 September 2004

\begin{abstract}
Soon after the 21 May 2003 Zemmouri (Algeria) earthquake that had stricken mainly Boumerdes and Algiers prefectures, inventory investigations were conducted on the existing constructions and facilities in order to evaluate losses and damages that affected these areas. This paper presents observations and analyses concerning a locality judged to be typical and might be considered as a case for the entire affected prefectures. A recently urbanized small zone of approximately $4 \mathrm{~km}^{2}$ located in Algiers Prefecture and near the border of Boumerdes Prefecture was investigated in detail. A total of 725 buildings were evaluated. Analysis of the collected data showed that damage was randomly distributed in the area. This result strengthens the assumption of low-quality materials and inadequate design, in relation to other assumptions, such as the effect of soil conditions. Reinforced concrete constructions were the most affected among the various other types, with approximately $18 \%$ of constructions of this type having suffered moderate to heavy damage. Data analyses showed that the most affected constructions were those in the range from 5 to 6 stories while buildings with only one story did not suffer any damage. Typical observed damages were, for the most part due to poor longitudinal and/or transversal reinforcements in the columns, very poor concrete quality, lack of shear reinforcements at beamcolumn joints, soft stories, pounding and the formation of short columns. Restoration of facilities and retrofitting practice on damaged buildings are reviewed in some cases.
\end{abstract}

\section{Introduction}

On 21 May 2003, at 19:45 local time, the northerncentral part of Algeria, which lies near the borderline separating the African Plate from the Eurasian Plate, experienced a severe earthquake of magnitude $6.8(\mathrm{Mw})$. The epicenter was seven kilometers north of Zemmouri city in Boumerdes Prefecture, and 60 kilometers east of Algiers, the capital (CRAAG, 2003). The earthquake's strong tremors reached even Europe, where they were felt in many countries on the northern side of the Mediterranean Sea (EQnet, 2003).

The analyzed records showed that the period of strongest motion lasted approximately 10 seconds and frequencies were concentrated in the band of 4 to $10 \mathrm{~Hz}$. In some locations, impressive accelerations were recorded beyond $0.4 \mathrm{~g}$ for vertical components and $0.58 \mathrm{~g}$ (Fig. 1) for horizontal components (Laouami et al., 2003). The main shock was followed by severe tremors with high magnitudes, inducing severe damages and disturbing and/or disrupting services, facilities and lifelines in the region. Some of the facilities withstood all the tremors, others withstood the main tremor but collapsed during the aftershocks, while some others still collapsed at the first tremors (GECOTEC, 2003). The worst affected prefectures were Boumerdes and Algiers

${ }^{1} \mathrm{Ph}$. D. Student, Department of Architecture, The University of Tokyo, Tokyo, Japan.

E-mail: oushas@eri.u-tokyo.ac.jp

${ }^{2} \mathrm{Ph}$. D. Student, Department of Architecture and Architectural Systems, Kyoto University, Kyoto Japan.
(Fig. 2). Officially, 2,278 persons died, 11,450 suffered injuries, and more than 180,000 were made homeless. Some 10,280 constructions collapsed, resulting in direct economic loss amounting to US\$5 billion as first estimation of (CNGC, 2003).

As usual in such catastrophes and in order to help public authorities make decisions and take urgent measures, a technical survey campaign was launched from the second day to assess damages and losses, carry out social relief measures, plan for temporary dwellings and housing reconstruction, and proceed to the repair and retrofitting of moderately damaged buildings and the demolition of heavily damaged ones. The inventory process was carried out in conformity with a standard technical form similar to a certain extent to the European Macroseismic Scale (EMS) one (ESC, 1998). Local and foreign academics and experts established this

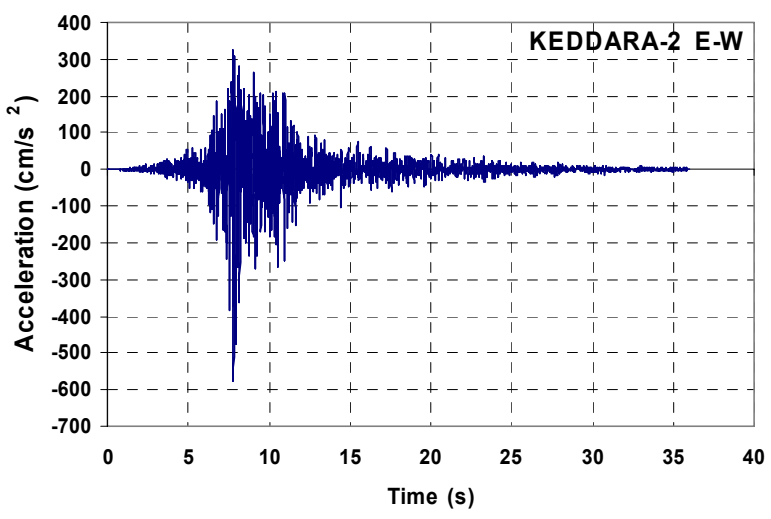

Fig. 1 Recorded horizontal acceleration at Kedara site. 


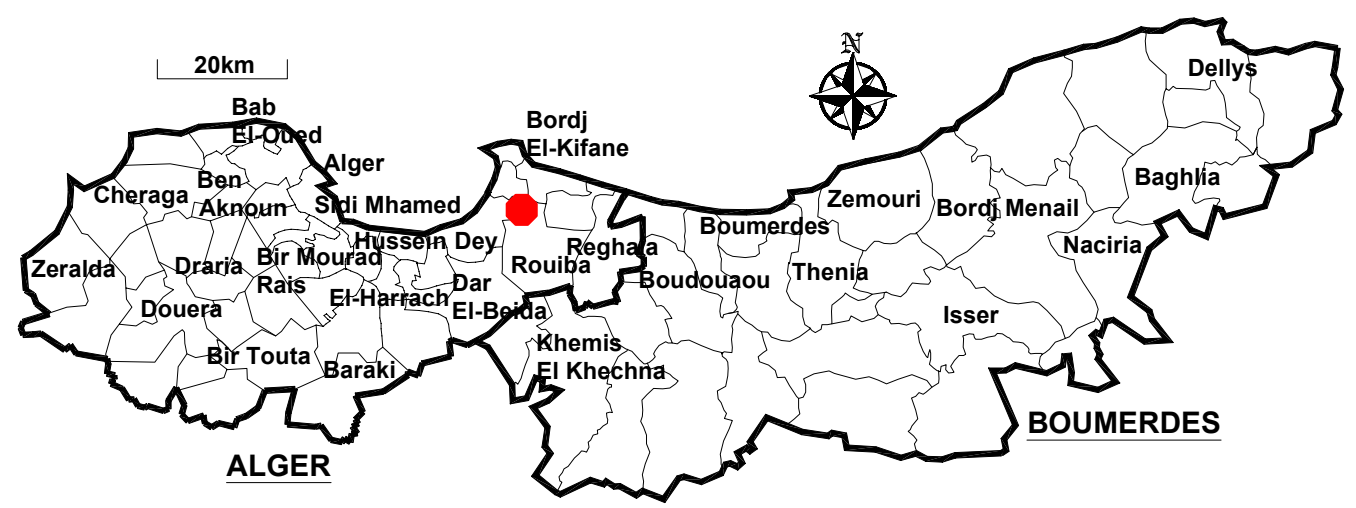

Fig. 2 Administration localities in Algiers and Boumerdes prefectures - Location of Dergana area (filled polygon shape).

construction evaluation form following the El-Asnam earthquake in 1980.

Subsequently, information concerning all the inventoried patrimony would be collected, tabulated and used for administrative, social and academic purposes. However, following the Zemmouri earthquake, for not fully known reasons, this task was not well accomplished. This led to some confusion in dealing with the inventory process, information and gathered technical data. While administration and social services would benefit to some extent from the collected information, academics have experienced difficulties extracting useful information from the spotty data that is available. To overcome the lack of detailed and precise data, authors made a field-scan of all the affected areas in the two prefectures of Boumerdes and Algiers and went on to perform detailed investigations on buildings in the Dergana zone, a region in Algiers Prefecture near the border with Boumerdes Prefecture (Fig. 2). Data analysis of the selected region, which was judged typical and adequate enough for achieving general conclusions for all the affected areas, revealed a number of important points. The findings are presented below.

\section{Dergana zone}

The Dergana region, distant from the epicenter by almost 40 kilometers, is a suburb in Dar El-Beida, a subprefecture of Algiers Prefecture. A relatively recent small-urbanized zone of approximately $4 \mathrm{~km}^{2}$, it is settled on relatively flat land and characterized by generally good soil conditions. Due to in-situ conditions and time constraints, the authors carried out a detailed investigation covering half of the Dergana area (Fig. 3).

The Dergana area was selected because it contains almost all types of constructions in terms of structural systems, materials and even damage types. The area was divided into 12 zones (Fig. 3). The evaluation of damage was based on a technical form, nearly identical to the European Macroseismic Scale of damage (ESC, 1998), filled out in the field (Ousalem and Bechtoula, 2003). The classification of damage to buildings fol-

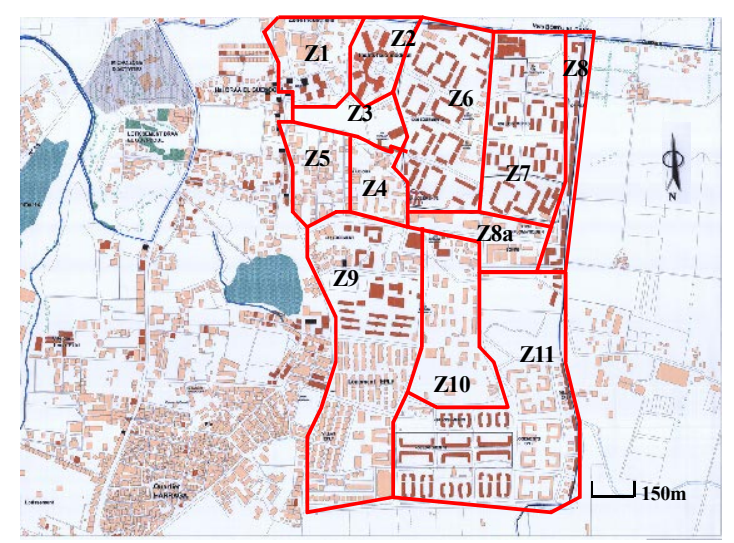

Fig. 3 Map showing different zones of the selected part in Dergana area.

Table 1 Classification of damage.

\begin{tabular}{|c|l|}
\hline Grade & \multicolumn{1}{|c|}{ Description } \\
\hline 1 & $\begin{array}{l}\text { Negligible to slight damage in non-structural } \\
\text { elements and no damage in structural elements }\end{array}$ \\
\hline 2 & $\begin{array}{l}\text { Moderate damage in non-structural elements } \\
\text { and slight damage in structural elements }\end{array}$ \\
\hline 3 & $\begin{array}{l}\text { Heavy damage in non-structural elements and } \\
\text { moderate damage in structural elements }\end{array}$ \\
\hline 4 & $\begin{array}{l}\text { Very heavy damage in non-structural elements } \\
\text { and heavy damage in structural elements }\end{array}$ \\
\hline 5 & $\begin{array}{l}\text { Very heavy damage in structural elements or } \\
\text { collapse of some parts or floors }\end{array}$ \\
\hline $\mathrm{C}$ & \begin{tabular}{l} 
Total collapse \\
\hline
\end{tabular} \\
\hline
\end{tabular}

lowed different technical criteria resulting in five grades, ranging from negligible or slight damage (Grade -1) to very heavy damage or collapse (Grade -5). Table 1 summarizes this classification and the general criteria. 
A total of 725 buildings were evaluated. The number of buildings in each of zones 1 to 11 were 10, 10, 4, 25, $65,66,111,21,21,189,18$ and 185 , respectively. It is important to mention here that the investigation could not be accomplished fully in Zone 1 because of the presence of private industrial buildings, the premises of which the authors were not allowed to enter.

\section{Typical damage and causes}

According to the observations made in the field, the damage level was different from place to place in the inventoried area. The main causes of observed damage are covered in greater detail in a companion paper (Bechtoula and Ousalem, 2005) and may be summarized as follows:

1. Presence of soft stories

2. Large spacing of shear reinforcement in the elements near joint zones

3. Absence of shear reinforcement in beam-column joints

4. Undersized element sections and insufficient longitudinal reinforcement

5. Damage due to collapse of adjacent buildings

6. Creation of short columns

7. Weak concrete strength and lack of confinement

8. Insufficient seismic joints and hammering problems

9. Collapse of masonry infill walls and prefabricated RC panels

10. Lack of design and underestimation of seismic hazard

11. Non-engineered constructions and lack of control

12. Absence of continuous and appropriate maintenance of existing buildings

\section{Distribution of damage}

\subsection{Distribution by zone}

According to observations, the analysis of the collected data and information, damage levels, shown in Fig. 4, were randomly distributed in the area, as illustrated in Fig. 5. This result strengthens the assumption of lowquality materials and inadequate design, in relation to other assumptions, such as the effect of soil conditions. Total collapse of a small number of constructions was observed in Zone 1 and Zone 11 while partial collapse (first floor, generally) was observed in Zone 5.

\subsection{Distribution by material type}

Although different materials were used for buildings, the majority $(75 \%)$ of constructions were made of reinforced concrete (Fig. 6). Fig. 7 illustrates the damage level related to construction materials. It is clear that reinforced concrete constructions were the most affected among the various types with $18 \%$ of such constructions suffering a level of damage to Grade 3 or higher. Typical observed damages were for the most part due to poor longitudinal and/or transversal reinforcement in the col-

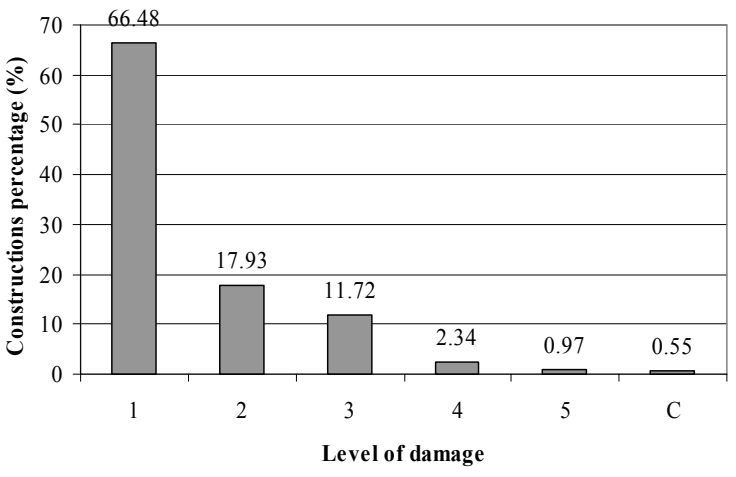

Fig. 4 Distribution of damage on buildings in Dergana.

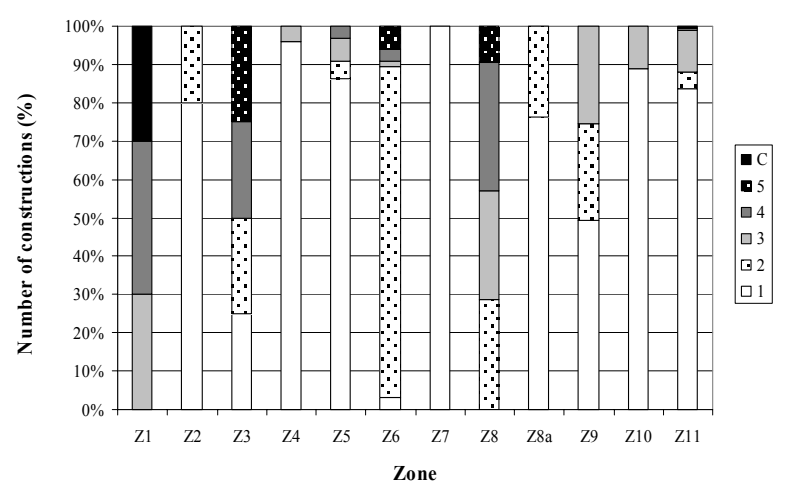

Fig. 5 Distribution of damage in each zone.

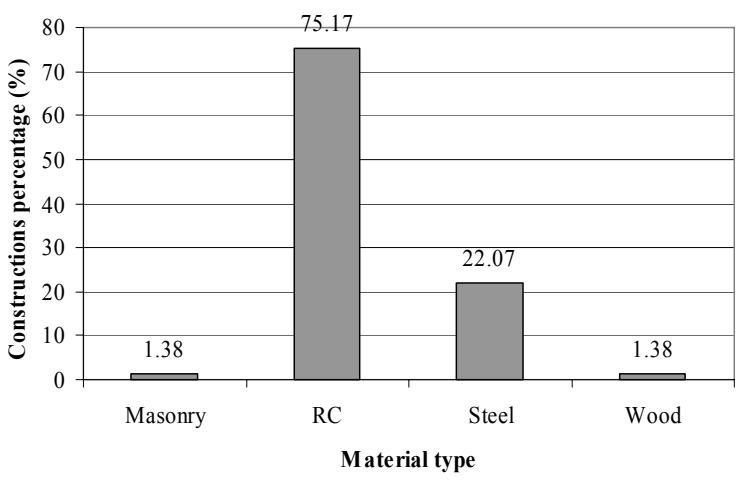

Fig. 6 Distribution of total number of inventoried buildings by material category (Notation: $\mathrm{M}=$ Masonry, $\mathrm{RC}=$ Reinforced Concrete, S= Steel, W: Wood).

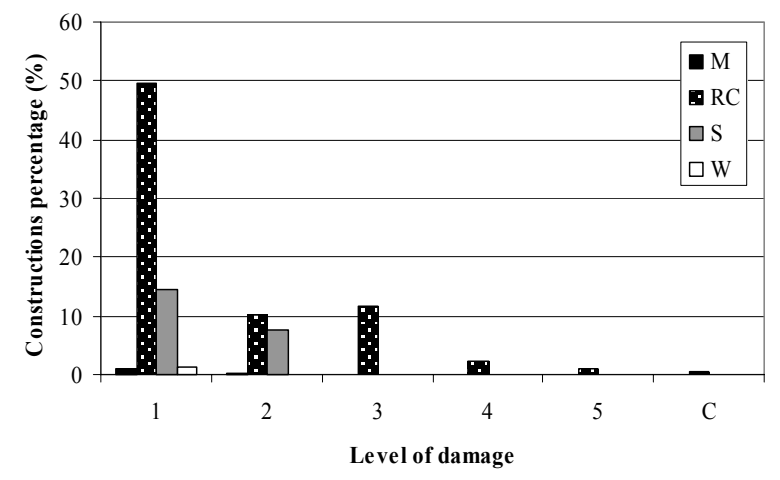

Fig. 7 Distribution of damage on buildings by material category. 


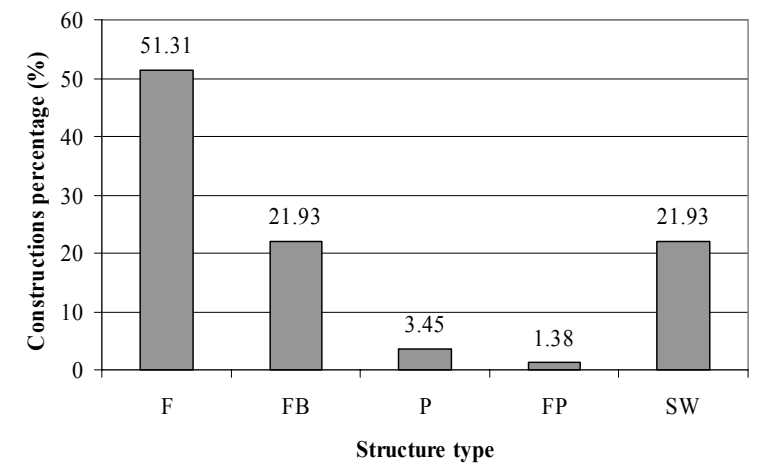

Fig. 8 Distribution of total number of inventoried buildings by structure category (Notation: $F=$ Frame, $F B=$ Frame+Bracings, $\mathrm{P}=$ Prefabricated, $\mathrm{FP}=$ Frame+Prefabricated Panels, SW= Shear Wall).

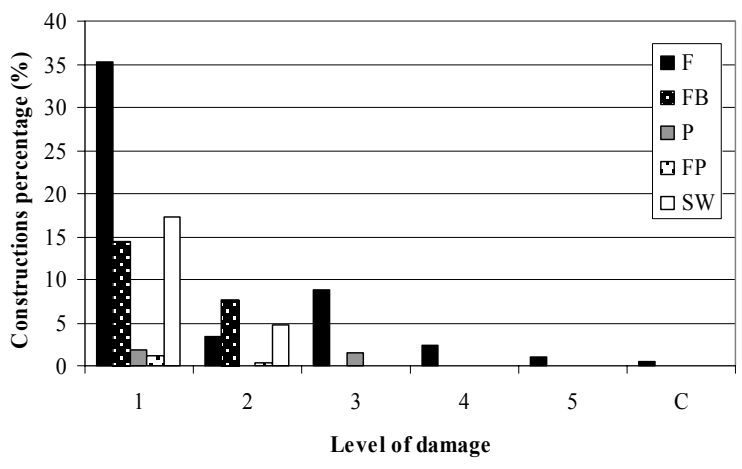

Fig. 9 Distribution of damage on buildings by structure category.

umns, very poor-quality concrete, mistakes in the arrangement of reinforcing bars, flexible first floors, pounding, and the formation of short columns.

\subsection{Distribution by structure type}

The distribution of different structural systems erected in the inventoried area is given in Fig. 8, which shows the high proportion of frame structures, a preferred construction system in Algeria, particularly for private housing. Distribution of damage levels related to existing structural systems (Fig. 9) revealed the weakness of the reinforced concrete frame system (F) compared to the shear wall system (SW) or the combined frame/bracing system (FB). Actually, buildings with braced-steel frame structures (FB) and shear wall structures (SW) responded very well during the earthquake and were able to absorb its induced energy. No human losses or damages were reported for such constructions.

\subsection{Distribution by number of floors}

The most common type of apartment buildings in the inventoried area have between 4 and 6 stories while private housing ranges from 1 to 3 stories. Other types of facilities generally consist of one story, with an exception sometimes for educational facilities, which may feature between 1 and 3 stories. Fig. 10 illustrates the distribution of buildings according to the number of floors.

Data analysis showed that the most affected constructions were those in the range of 5 to 6 stories. Buildings with 2 and 3 stories generally, experienced slight to heavy damage, while constructions with one story did not suffer any damage (Fig. 11). This may be correlated to the frequency content of recorded accelerograms, which was very rich in the range of 4 to $10 \mathrm{~Hz}$ (Laouami et al., 2003).

\subsection{Distribution by construction period}

As illustrated in Fig. 12, the number of constructed

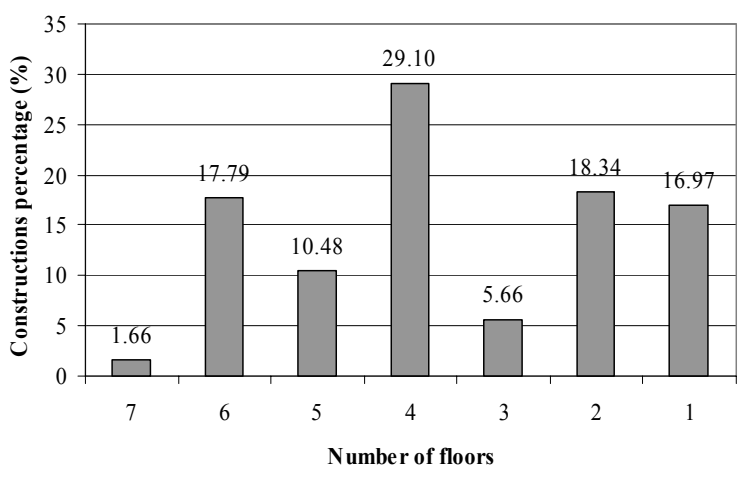

Fig. 10 Distribution of total number of inventoried buildings by floor category.

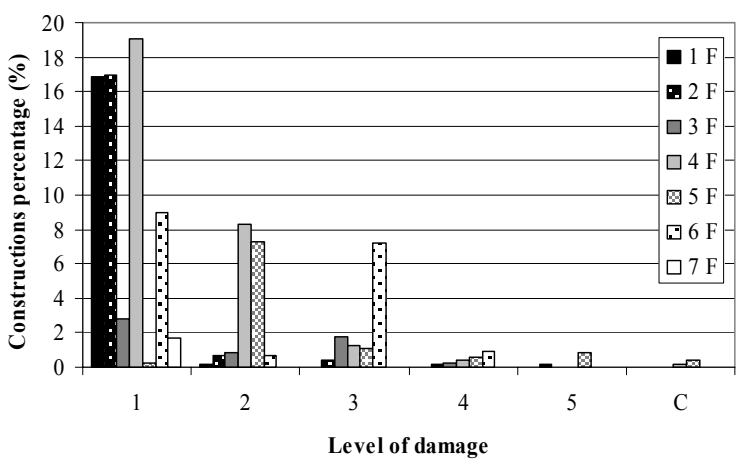

Fig. 11 Distribution of damage on buildings by floor category.

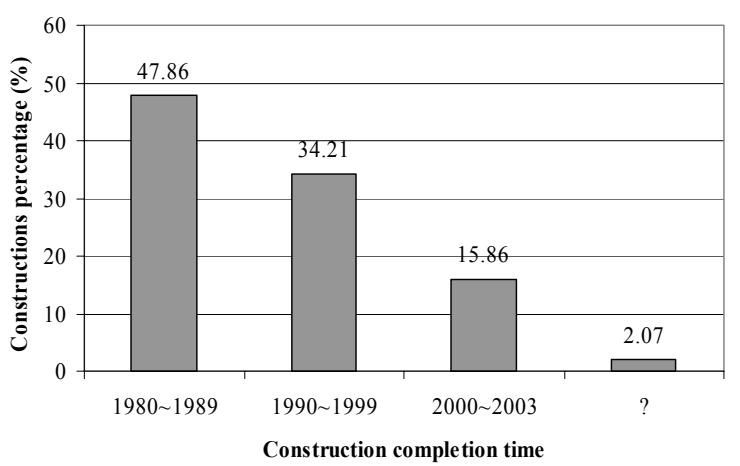

Fig. 12 Distribution of total number of inventoried buildings by building period. 
buildings has been decreasing every year since 1980 . Actually, the government built the majority of the apartment buildings in the area in the early 80 s. From the end of this government-building period, the number of private houses increased compared to public housing. During the 90s, the country experienced political problems and anarchy spread in the administrations in charge of constructions and as a consequence many structures were erected without following standards such as design, site control and quality of materials. Figure 13 clearly shows that the most affected constructions were those built in the 90 s or later.

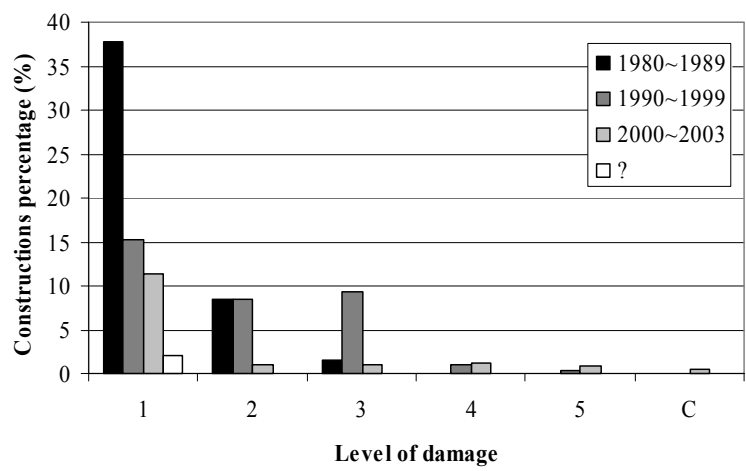

Fig. 13 Distribution of damage on buildings by building period category.

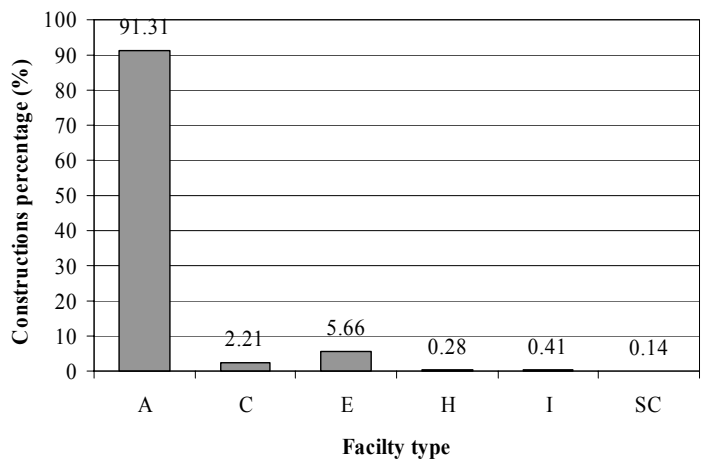

Fig. 14 Distribution of total number of inventoried buildings by facility type.

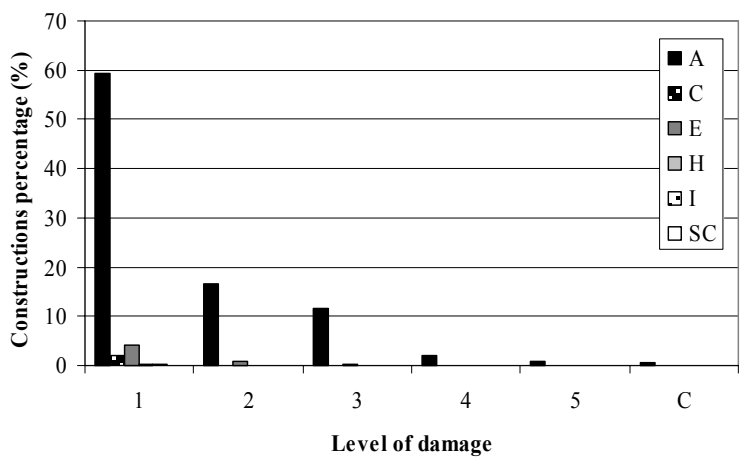

Fig. 15 Distribution of damage on buildings by facility type (Notation: $A=$ Apartment buildings, $C=$ Commercial, $\mathrm{E}=$ Educational, $\mathrm{H}=$ Health centers, $\mathrm{I}=$ Industrial, $\mathrm{SC}=$ Socio-Cultural).

\subsection{Distribution by facility type}

The inventoried area, which is considered as a residential area, contains mainly apartment buildings (A) along with a number of basic facilities such as schools (ED), commercial centers $(\mathrm{C})$ and health centers $(\mathrm{H})$ (Fig. 14). Apart from apartment buildings and educational facilities, other facilities did not experience even moderate damage, as shown in Fig. 15.

Apartment buildings were the structures most damaged by the earthquake, followed by educational facilities. It is worth mentioning here that no educational facility collapsed in the area.

\section{Quality of concrete and steel}

An investigation on the quality of materials was carried out in the Dergana area, principally for concrete, where the concrete strength ranged from 10 to $30 \mathrm{MPa}$ for columns and approximately $18 \mathrm{MPa}$ for beams and slabs. Generally, columns are cast using manpower when their number is limited, especially for small houses, causing a large spread in concrete strength values. However, since a large volume of concrete is needed to cast floors, mechanical equipment is used instead, resulting in a slight variation in concrete strength and higher values than those observed in columns.

As to steel reinforcements, some information revealed the wide of imported steel not adequate for construction in various projects and areas. However, some steel bars (D10) were taken from Zone 5 in Dergana (Fig. 3) and tested, with the results revealing good characteristics as shown in Table 2. Figure 16 represents the behavior of one of the tested bars.

Table 2 Summary of mechanical characteristics of tested bars.

\begin{tabular}{|c|c|c|c|}
\hline Rebars & $\sigma_{\mathrm{y}}(\mathrm{MPa})$ & $\varepsilon_{\mathrm{y}}(\%)$ & $\sigma_{\mathrm{f}}(\mathrm{MPa})$ \\
\hline 1 & 490.3 & 0.289 & 617.4 \\
\hline 2 & 505.5 & 0.288 & 608.9 \\
\hline 3 & 519.9 & 0.296 & 626.7 \\
\hline
\end{tabular}

( $\sigma_{\mathrm{y}}$ : yielding stress, $\sigma_{\mathrm{f}}$ : fracture stress, $\varepsilon_{\mathrm{y}}:$ yielding strain)

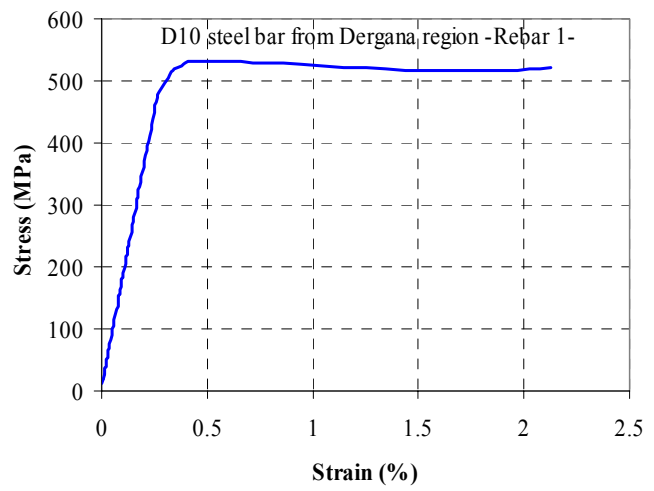

Fig. 16 Stress-strain relationship of a tested bar. 


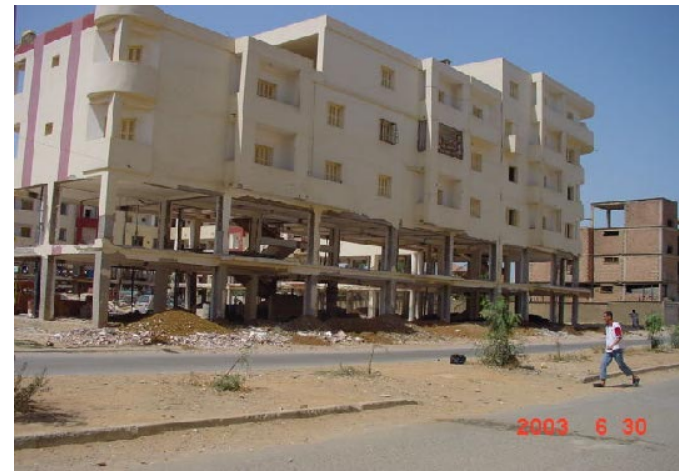

Fig. 17 Taking out of damaged infill walls.

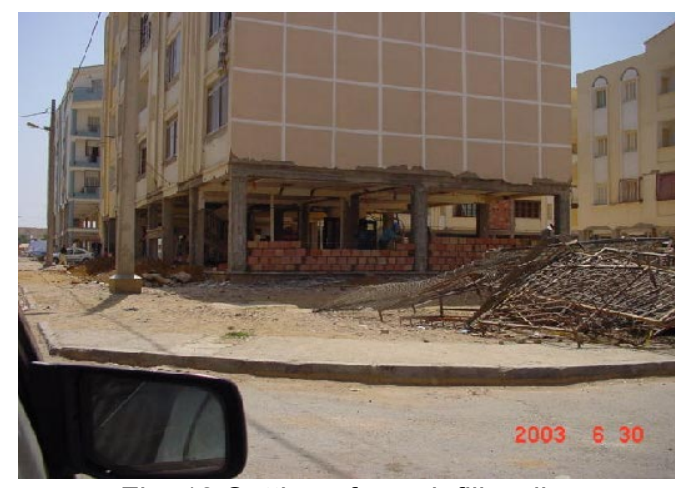

Fig. 18 Setting of new infill walls.

\section{Restoration phase and retrofitting practice}

Following the earthquake, repair and retrofitting of damaged constructions were carried out to allow a rapid return to normal. Many public and private design and construction companies were involved in the process.

In the case of slightly damaged constructions, where only non-structural elements were affected, for instance hollow brick infill walls, damaged elements were taken out and replaced with new ones as shown on Fig. 17 and Fig. 18.

In the case of moderately to severely damaged constructions, where non-structural and structural elements such as beams, columns and shear walls, were affected, damaged elements were repaired or replaced and in some cases, additional new structural elements, generally shear walls, were inserted into existing structures to upgrade the lateral performance of existing buildings for future seismic events. Two different cases, located in Dergana city and shown on the map in Fig. 19, are given hereafter as examples for retrofitted buildings.

\subsection{Case 1}

The first case consists of two buildings. Retrofitting work was carried out on an L-shaped corner building and an edge rectangular building. Fig. 20 shows an overview of these buildings.

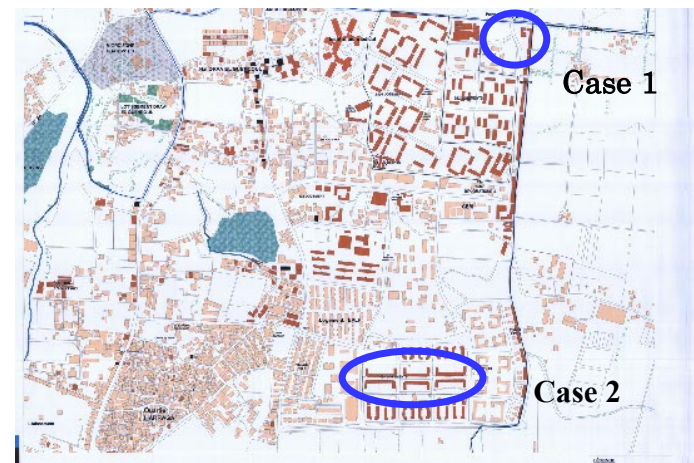

Fig. 19 Localization on the map of two studied cases.

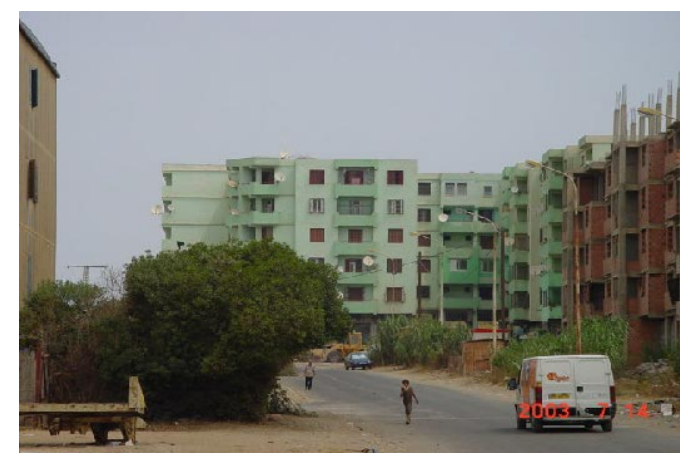

Fig. 20 General view of the corner and edge buildings.

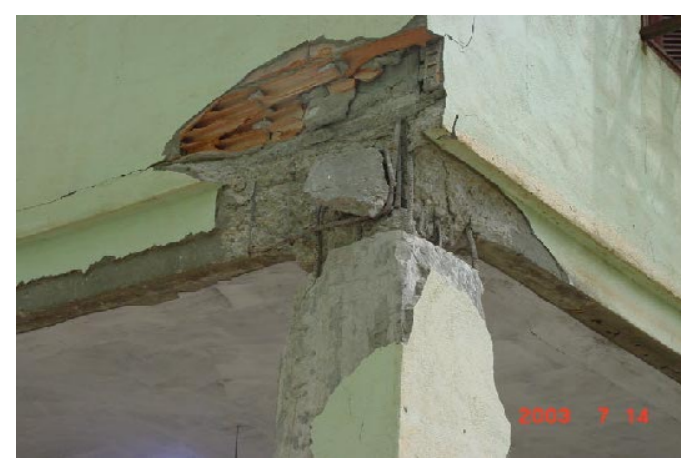

Fig. 21 Damage to a column of the corner building.

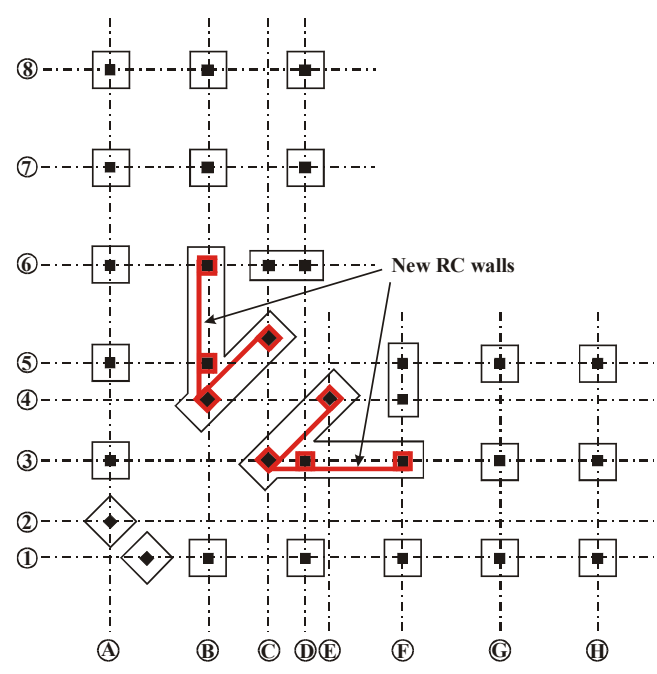

Fig. 22 Location of the inserted walls into the corner building. 


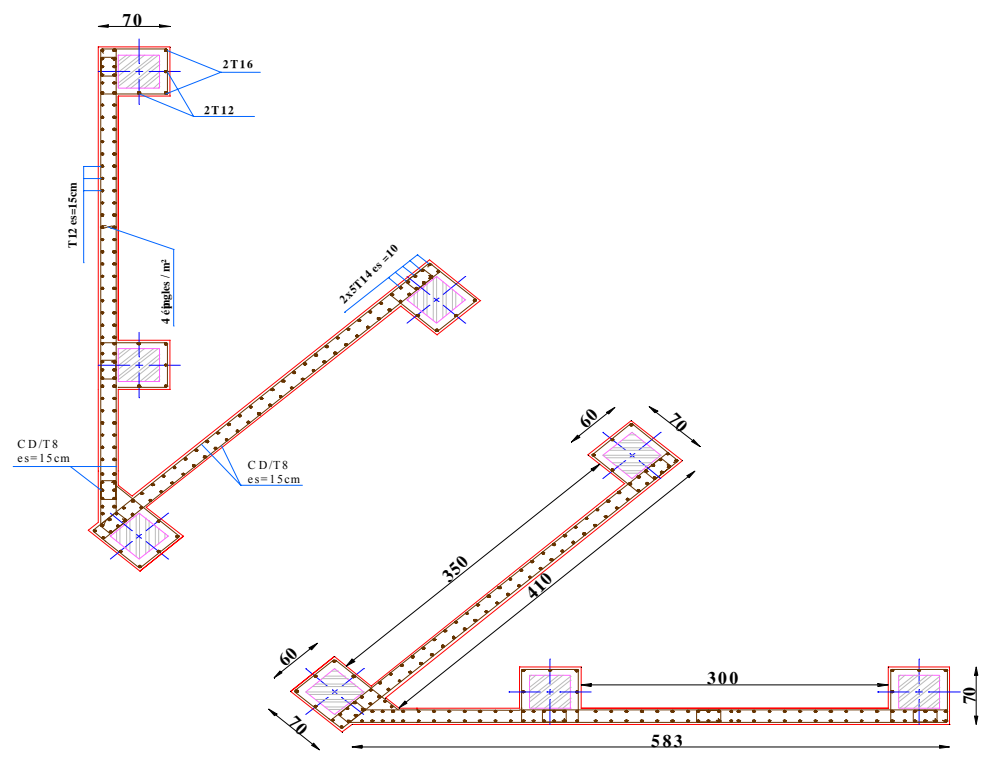

Fig. 23 Detail of added reinforced concrete walls.

\subsubsection{Corner building}

This building was severely damaged at the top of columns as shown on Fig. 21.

The retrofitting solution consisted in adding new reinforced concrete shear wall elements over the whole height of the building. The new elements are designed according to the new RPA99 seismic regulations, to relieve the repaired reinforced concrete frame from forces induced by probable future earthquakes. The new $\mathrm{RC}$ shear walls disposition is shown in Fig. 22. Details of the connection between the old and the new structural systems are also given in Fig. 23. At the time of the inspection of the buildings, a good part of the retrofitting phase had already been accomplished, as shown in Fig. 24.

\subsubsection{Edge building}

The rectangular building shown on Fig. 25 did not suffer as much damage as the corner building. Adding new $\mathrm{RC}$ shear walls to the existing frame structure was found to be an adequate solution to provide resistance to horizontal loads in the future and restrict displacement

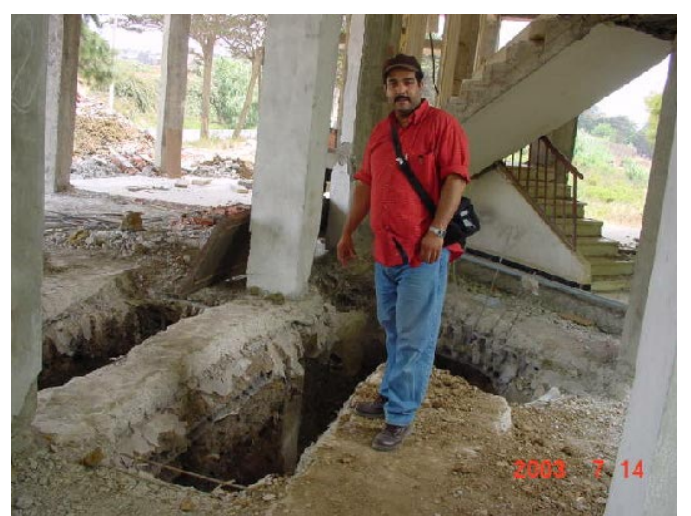

Fig. 24 Preparations phase - Insertion of RC shear walls. to avoid pounding. In total, four RC shear walls were planned for addition, in a symmetric arrangement, to the structure, as illustrated in the drawing shown in Fig. 26.

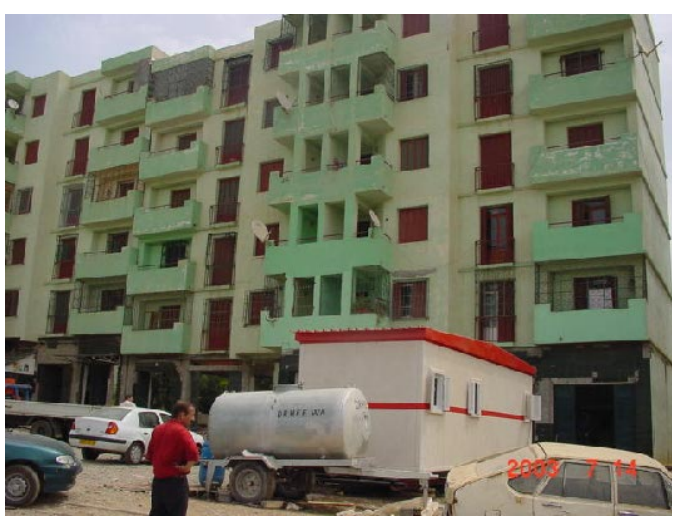

Fig. 25 External view of the rectangular building.
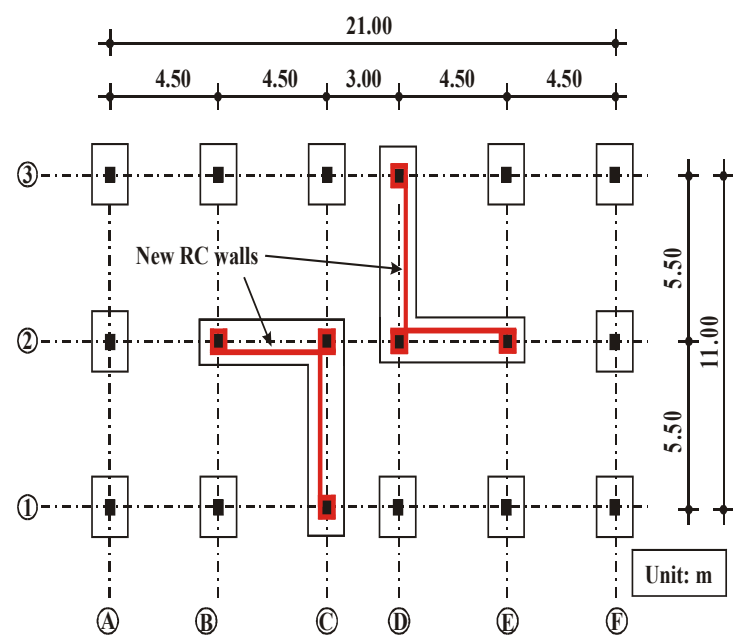

Fig. 26 Location of the walls inserted into the rectangular building. 


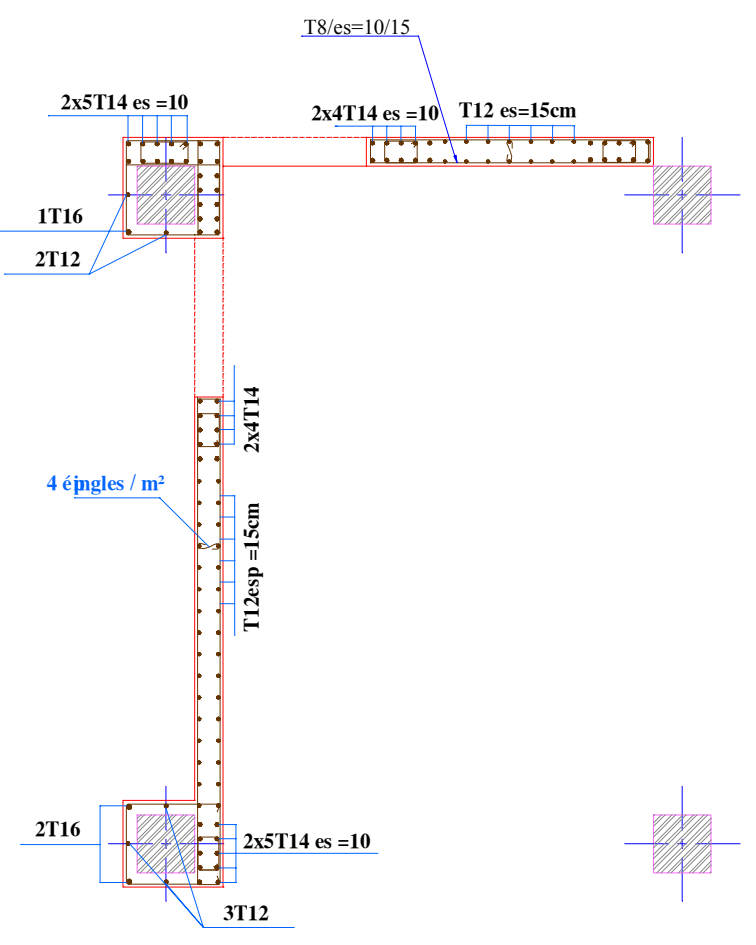

Fig. 27 Detail of added reinforced concrete shear walls.

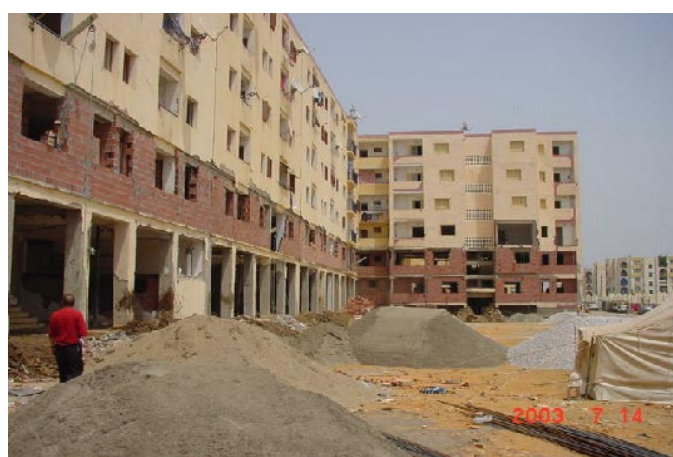

Fig. 28 Renew of the damaged masonry infill walls.

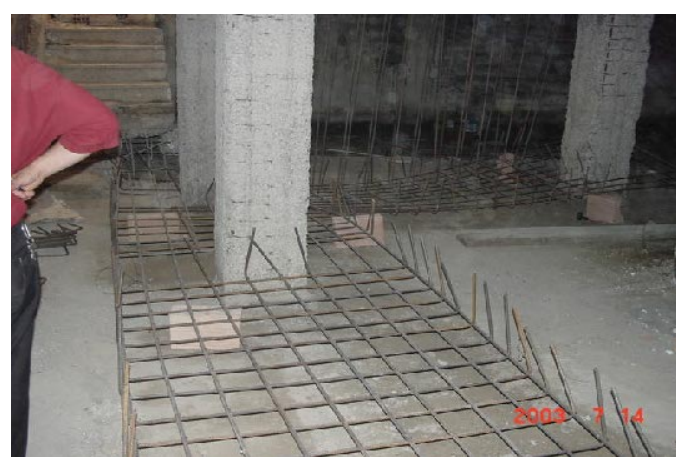

Fig. 29 Details of the new foundation's reinforcement.

Details of the new reinforced concrete shear wall are shown in Fig. 27.

\subsection{Case 2}

The second case consists of retrofitting six long 5-story

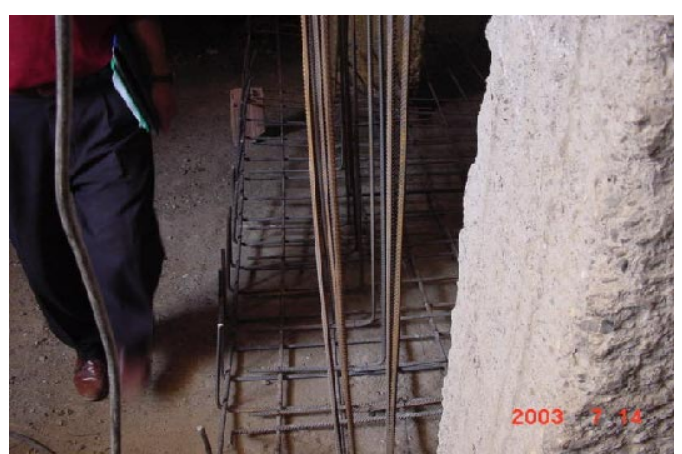

Fig. 30 Connection between the foundation and the wall's reinforcements.

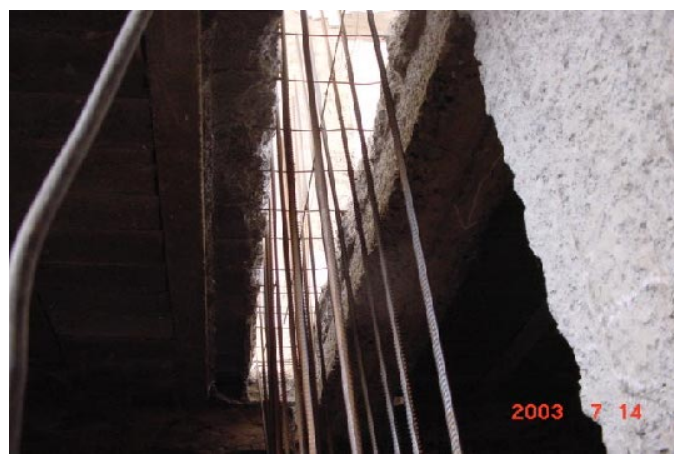

Fig. 31 Detail between the slab and the new RC walls.

reinforced concrete frame buildings with basements by inserting new RC shear walls over the total height of the building from the basements. First, the damaged masonry infill walls were removed and substituted by new 
ones as shown in Fig. 28. Continuous new foundations were planned for execution and serve as the base for the new RC shear walls (Fig. 29).

The new structural elements were linked to the existing columns and beams, which were roughened to increase the adhesion between the existing and the new structures, as shown in Fig. 30 and Fig. 31.

\section{Conclusions}

The May 21st, 2003, Zemmouri earthquake caused heavy damage. Almost all old buildings collapsed, particularly stone masonry buildings.

Reinforced concrete frame buildings suffered serious damage compared to other types of structures, and shear wall structures and steel frame buildings experienced no damage.

A large number of private housing and apartment buildings that were constructed recently by private contractors collapsed and in the best case suffered significant damage.

While the damage was owed sometimes to deficiencies in the seismic code and old construction practices for constructions designed before 1981, the damages observed in recently constructed buildings may only be explained by the quality of materials, the quality of construction and the absence of control.

Although there are insufficiencies in the Algerian seismic regulations (IAEE, 1992 and 2000), proper application of the prescriptions and techniques given in the code would have prevented to a significant extent the physical damage and loss of human life for recently constructed buildings during the Zemmouri earthquake. However, for existing old constructions and buildings that did not satisfy the requirements of new seismic regulations, the high damage level observed in the affected areas was inevitable, with some exceptions. While in some areas some buildings collapsed, other neighboring well-designed existing buildings withstood the earthquake well due to the relative relation linking applied forces to available strength in these constructions. This fact could also be explained by the good quality of building materials as well as the good quality of construction process and probably efficient site control.

\section{Acknowledgements}

The authors gratefully acknowledge the extensive support provided by Professor Toshimi Kabeyasawa from the Earthquake Research Institute, The University of Tokyo, and Professor Fumio Watanabe from Kyoto University. Their laboratories' financial support made site visits and investigations possible. The assistance received from engineers and CGS's members in Algeria is also acknowledged.

\section{References}

Bechtoula, H. and Ousalem, H. (2005). "The 21 May 2003 Zemmouri (Algeria) earthquake: Damages and disaster responses" Journal of Advanced Concrete Technology, Japan Concrete Institute, 3 (1), 161-174.

CNGC (2003). "Séisme du 21 mai 2003 [online]." Algeria, Cellule Nationale de Gestion de la Crise. Available from: <http://www.seismealgerie2003.dz/> [Accessed 15 July 2003].

CRAAG (2003). "Séisme du 21/05/2003 Région de Boumerdes [online]." Algeria, Centre de Recherche en Astronomie, Astrophysique et Géophysique. Available from: <http://www.craag.edu.dz/> [Accessed 13 July 2003].

EQnet (2003). "Algiers, Algeria Earthquake, May 21, 2003 [online]." United States of America, EarthQuake Information Network. Available from: $<$ http://www.eqnet.org/FMPro/Web/archives/algiers.h tm> [Accessed 15 July 2003].

ESC (1998). European Seismological Commission, Subcommission on Earthquake Seismology, Working Group Macroseismic Scales, "European Macroseismic Scale, EMS-98." Cahiers du Centre Européen de géodynamique et de Séismologie, Volume 15, Grünthal, Luxembourg.

GECOTEC (2003). "Séisme du 21 mai 2003, AlgerBoumerdes [online]." Algeria, Groupement Economique de Contrôle Technique de la Construction. Available from <http://www.gecotecdz.com/caracterisation.htm $>$ [Accessed 20 July 2003].

IAEE, International Association for Earthquake Engineering (1992). "Earthquake Resistant Regulations - A World List - 1992.” Japan, 1.1-1.34.

IAEE, International Association for Earthquake Engineering, (2000). "Earthquake Resistant Regulations - A World List - 1996, Supplement2000.” Japan, 2.1-2.36.

Laouami, N., Slimani, A., Nour, A. and Larbes, A. (2003). "Résultats préliminaires sur la caractérisation du séisme de Boumerdes du 21 mai 2003 (Choc principal)." Centre National de Recherche Appliquée en Génie Parasismique.

Ousalem, H., Bechtoula, H. (2003). "Report on the Damage Investigation and Post-Seismic Campaign of the 2003 Zemmouri Earthquake in Algeria." Earthquake Research Institute, The University of Tokyo, Ohbunsha Press. 